\title{
Types of dialogue and pragmatic ambiguity
}

\author{
Fabrizio Macagno \& Sarah Bigi \\ In Steve Oswald, Thierry Herman, Jérôme Jacquin (eds.), Argumentation and Language — Linguistic, \\ Cognitive and Discursive Explorations, Amsterdam: Springer
}

Since the first sophistic theories, the concept of ambiguity has been investigated in relation to its role in natural language, and in particular to the communicative and argumentative problems or strategies that result from the different interpretations of an utterance (Aristotle, Topics, 112b 22). From a linguistic point of view, ambiguity is crucially related to the problem of establishing the best interpretation of a speech act (Atlas and Levinson 1981; Atlas 2008). On this view, ambiguity is not only the possibility of ascribing different meanings to a lexical item. Instead, it needs to be considered in a broader picture as the actual or potential disagreement or uncertainty concerning the meaning to be attributed to an utterance in a specific context. In this sense, misunderstanding and ambiguity concern utterances performed in a specific context, considering not only the "prehistory" of an utterance (Mey 1993, 13) but more importantly the purpose of the conversation and the pretended function of the utterance within it, and the institutional and cultural factors that contribute to the meaning.

The purpose of this paper is twofold. We pursue a theoretical goal, as we aim at providing an instrument for detecting, analyzing, and solving ambiguities based on the reasoning mechanism underlying interpretation. To this purpose, we combine the insights from pragmatics and argumentation theory and represent the background assumptions (namely the contextual factors considered in the broader sense, see Mey, 2003, 1993) driving an interpretation as presumptions. Presumptions are in turn shown to constitute the backbone of the argumentative reasoning that is used to assess and solve ambiguities and drive (theoretically) interpretive mechanisms. Our claim is that in case of interpretive disputes or misunderstanding, the various contextual presumptions need to be confronted and their defeasibility conditions assessed. The "best interpretation" is thus the less defeasible one considering all the contextual presumptions.

Our second purpose is practical. By analyzing ambiguities as stemming from different presumptions concerning language or more importantly expected communicative roles and goals, we can use communicative misunderstandings as the signal of deeper disagreements concerning mutual expectations or deeper cultural differences. This argumentation-based interpretive mechanism will be applied to the analysis of medical interviews in the area of diabetes care, and will be used to bring to light the sources of misunderstanding and the differences in the presumptions (epistemic, linguistic, evaluative, etc.) relied upon (Flores 2000; Angelelli 2004; Kecskes and Zhang 2009; Kecskes and Zhang 2013; Kecskes 2015) ${ }^{1}$.

In this paper, we apply the theoretical framework consisting of the presumptive mechanism of interpretation and the types of dialogue to the analysis of a corpus of medical conversations. We illustrate the analytical tools by identifying and distinguishing the various types of ambiguity underlying misunderstandings, and we address them by describing the communicative intentions ascribed to the ambiguous utterances. The presumptions guiding the conflicting interpretations are brought to light, showing the cultural differences at various levels of reasoning and communication.

\footnotetext{
${ }^{1}$ We argue that that such different presumptions define distinct cultures, building on Kecskes's broader notion of culture as "a system of shared beliefs, norms, values, customs, behaviors, and artifacts that the members of society use to cope with their world and with one another” (Kecskes 2013, 4).
} 


\section{Ambiguity, misunderstandings, and context}

Misunderstanding and miscommunication are rooted in the crucial notion of ambiguity. Ambiguity is a widely discussed concept in pragmatics (Sperber and Wilson 1986; Atlas 1989; Jaszczolt 1999; Levinson 2000; Atlas 2005; Saka 2007) and argumentation theory (Walton 1996a; van Laar 2003; Walton 2006). While the studies in philosophy of language focus on how ambiguities are processed, works in the field of argumentation mostly address the sources of ambiguities, their use for strategic or manipulative purposes, and the dialectical procedures for resolving them.

\subsection{Ambiguities and ambiguity resolution}

A fundamental distinction traced in both the field of argumentation and philosophy of language is the one between the level of semantic interpretation (sentence meaning) and the speaker's meaning, i.e. the output of further processing of sentence meaning considering various contextual factors. In this view, the semantic representation resulting from compositional semantics needs to be processed pragmatically, namely subjected to pragmatic processing aimed at solving ambiguity at different levels (Sperber and Wilson 1986; Levinson 2000). A first type of processing concerns disambiguation issues, such as the ones concerning lexical ambiguity or structural (syntactic) ambiguity. We consider the following examples of disambiguation (Levinson 2000, 174):

1. Lexical ambiguity (Lyons 1977, 550) (includes homonymic words and homographs):

a. The view could be improved by the addition of a plant out there

b. The view would be destroyed by the addition of a plant out there

2. Structural ambiguity (Prepositional-Phrase attachment)

a. Mary left [the book] [on the bus.]

b. Mary left [the book on the atom.]

c. He looked at the kids [in the park] with a telescope.

d. He looked at the kids [in the park with a statue].

Lexical and syntactic ambiguities (called also grammatical ambiguities) can result in sentences that are related to different semantic representations. On the contrary, semantic ambiguities "are characterized by a general semantic representation from which a truth-conditionally evaluable proposition can be derived by means of pragmatic rules” (Jaszczolt 1999, 2). Semantic ambiguities, in this sense, include interpretive phenomena distinguished from lexical or syntactic “disambiguation” (Levinson 2000, 174186; Atlas 2005, chap. 1), such as indexical resolution, reference identification, ellipsis unpacking, and generality narrowing. Such phenomena are related to the "underdetermination" of the semantic representation of a sentence (or "what is said") (Atlas 2005, 40), and govern the passage from a semantic nonspecific structure to a proposition that can carry a truth-value. We summarize the most important types of semantic ambiguity (as defined by Jaszczolt above) as follows:

3. Indexical resolution

a. Suppose A is in Los Angeles and B is in New York and the following exchange takes place:

A: "Where's the conference being held?"

B: "It's being held here." ("here" does not refer to the exact location of the speaker in that very moment, but rather to the university where the conference takes place)

4. Reference Identification 
a. Only Felix voted for him ("him” can refer to either Felix himself, or the candidate that does not correspond to Felix).

b. The king is powerful ("the king" can refer to the person who is the king at the time of the utterance or to the role of the king) (Bezuidenhout 1997; Jaszczolt 1999; Capone 2011)

5. Ellipsis Unpacking

a. A says "Who came?" and B replies "John" ("John” is elliptical and the whole sentence needs to be reconstructed, resulting in "John came")

6. Generality Narrowing

a. Fixing this car will take some time ("some time" means "longer than expected," otherwise it would be a tautology)

b. I've eaten breakfast ("I have eaten" means "I have just eaten" or "I have eaten breakfast this morning," and does not refer to the fact that the speaker is a breakfast eater)

In addition to semantic interpretation of context-oriented elements (indexicals, etc.), the reconstruction of "what is said" (or sentence-meaning) requires pragmatic (contextual) inferences (Récanati 1987, 224; Carston 2002a; Kissine 2012, 17), based on presumptions of different kind, including the goal and the topic of the conversation (Atlas 2005, 38). Once sentence meaning is reconstructed, further pragmatic processing leads to drawing implicatures.

The distinction between grammatical, semantic, and pragmatic ambiguity is mirrored by the studies in argumentation theory addressing the problem of ambiguity and equivocation.

\subsection{Levels of ambiguity and their argumentative effects}

In the studies of argumentation theory, three levels of ambiguity are distinguished: potential, actual, and imaginary (Walton 1996a, 262), which broadly correspond to the aforementioned distinctions between grammatical, semantic, and pragmatic ambiguity. Potential ambiguity includes lexical, syntactic, and intonational ambiguity, and refers to the grammatical elements that can result in ambiguity when taken out of co-text. On the contrary, actual ambiguity is ambiguity of use, i.e. concerns the phenomena involved in the interpretation of the sentence expressed by an utterance. Finally, imaginary ambiguity refers to the further implicatures that can be drawn from the utterance of a sentence in a specific context (van Laar 2001; van Laar 2003, chap. 4), but also the possible distinct interpretations of the intended effects on the interlocutor, i.e. the so-called "illocutionary" and "perlocutionary" effects. For example an utterance can be interpreted as a request or as an order, depending on the context; an assertion of a negative behavior can be taken as an accusation or as a complaint, depending on the type of dialogue the interlocutors are engaged in (Macagno 2016; Macagno and Capone 2016). Moreover, an utterance can be intended to result in accessory effects, such as reassuring, persuading, threatening, which do not constitute the effect performed by uttering the specific sentence (Searle 1976; Searle and Vanderveken 2005). An utterance can result ambiguous due to such effects ("I did not mean to offend you!").

A controversial issue in the classification of ambiguities concerns emphatic and intonational ambiguities. On Walton's approach, imaginary ambiguity includes not only perlocutionary and illocutionary ambiguity, but also the so-called emphatic ambiguity. This type of ambiguity is not clearly defined, but can be identified with the stress placed on a specific word or phrase ("VERY nice, isn't it?”; "He is an ITALIAN”) and leading to further implicatures (the speaker is sarcastic; he is expressing his contempt). To this purpose, we need to stress the distinction between emphatic ambiguity and the mere intonational one, which can concern also different theme-rheme (focus-topic) articulation, namely different syntactic structures that may be grammatically ambiguous if not 
disambiguated at the utterance level. For example, the sentence "Bob went to the party" may mean that it was Bob that went to the party, or that was the party the place where Bob went to, or that what Bob did was to go to the party. These different syntactic structures can be disambiguated by means of different intonations of the utterance (Reinhart 1981; Gundel and Fretheim 2004).

The different types of ambiguity can be summarized as follows (adapted from Walton, 1996a, p. 262):

\begin{tabular}{|c|c|c|c|}
\hline \multicolumn{4}{|c|}{ Potential ambiguity (grammatical ambiguity) } \\
\hline \multicolumn{2}{|c|}{ Lexical } & Syntactic & Intonational \\
\hline Homographs & $\begin{array}{c}\text { Different } \\
\text { definitions }\end{array}$ & Different syntactic construction & $\begin{array}{l}\text { Different deep structures } \\
\text { manifested by different } \\
\text { intonations }\end{array}$ \\
\hline \multicolumn{4}{|c|}{ Pragmatic ambiguity } \\
\hline \multicolumn{2}{|c|}{ Actual } & \multicolumn{2}{|c|}{ Imaginary } \\
\hline \multicolumn{2}{|c|}{ Semantic ambiguity } & Illocutionary and Perlocutionary & Emphatic \\
\hline
\end{tabular}

Table 1: Levels of ambiguity

Whereas potential ambiguity and propositional pragmatic ambiguity concern the level of what is said (Bezuidenhout, 1997; Carston, 2002, 2013; Soames, 2008), what is at stake in ambiguity at the illocutionary and perlocutionary level is the reconstruction of the pragmatic purpose of a speech act, namely what is meant. The same utterance can be interpreted as intended to produce different illocutionary or perlocutionary effects depending on the type of reconstruction and the factors taken into account in reconstructing its meaning.

This distinction is important for determining the level at which a strategy of equivocation occurs (Deppermann 2000). In particular, this distinction points out the role of context in disambiguating utterances. As Mey puts it (Mey 1993, 13):

Ambiguity only exists outside of the actual speaking situation; abstract sentences can be Ambiguous, real speakers are not (unless they want to) [...] Often, it is said that we must invoke the context to determine what an ambiguous sentence means. This may be OK, if by 'context' we understand all the factors that play a role in producing and understanding utterance.

On this view, the context - intended as the institutional setting, in addition to the conversational one and the co-text (the "history" of an utterance in a discourse) - determines the correct interpretation intended by the speaker (Mey 2003, 346). In this sense, pragmatic inferences can prevent ambiguities from arising (Jaszczolt 1999, 4); however, ambiguities can arise because not all the contextual factors on which the speaker relies in communicating his communicative or dialogical intentions (Grosz and Sidner 1986, 178) are shared by the hearer. Moreover, in cases of manipulation ambiguities are introduced by preventing the interlocutor from accessing all the contextual factors needed for a correct or univocal understanding of the utterance (Macagno 2016). Typical cases of such types of manipulative uses of ambiguity are the fallacies of straw man (Walton 1996b; Aikin and Casey 2011; Macagno and Damele 2013) and wrenching from context (Walton and Macagno 2010; Macagno and Capone 2016). 


\section{Presumptions and best interpretation}

The theories advanced in philosophy of language provide clear insights in how context and more importantly the presumptions resulting from various types of contextual factors contribute to determining the intended meaning. While the processing of utterances and the disambiguation processes involved are usually automatic, non-reflective (Patterson 2004; Wilson and Sperber 2004; Wilson 2016), when an interpretation is controversial or doubtful and needs explanation the reasoning underlying interpretation needs to be brought to light and analyzed (Dascal and Wróblewski 1988). The purpose of an argumentative approach to ambiguity thus does not only concern the analysis of the factors that, once concealed, can result in ambiguity, but also the argumentative reasoning in support of an interpretation that can be made explicit in case of dispute. In this section, we will address the problem of representing the argumentative reasoning used for supporting and evaluating an interpretation. This type of reasoning is intended to describe a dialogical mechanism for bringing to light and assessing the various factors that contribute to supporting or dismissing an interpretation.

\subsection{Presumptions and presumptive reasoning in interpretation}

The process of dialectical motivation (and theoretically, a possible dialectical model of reconstruction) of an interpretation of an utterance can be represented in terms of presumptions. On this perspective, normally utterances are processed relying on heuristic, presumptive mechanisms. On the relevancetheory approach, such mechanisms are cognitive in nature (Sperber and Wilson 1986; Wilson and Sperber 2004; Wilson 2016). On the contrary, in neo-Gricean and radical pragmatics accounts, such automatic processes are based instead on the content and the metalinguistic properties of an utterance (the utterance-type) (Levinson 2000, 6-7). While in the former approach the basic heuristics concern the maximization of the information, i.e. cognitive response vis-à-vis processing efforts, in the latter theories the content and the form of an utterance provides a preferential reading, which can be disconfirmed by other linguistic or contextual evidence. This view is expressed through the following heuristics (Levinson 2000, 7):

1. If the utterance is constructed using simple, brief, unmarked forms, this signals business as usual, that the described situation has all the expected, stereotypical properties;

2. If, in contrast, the utterance is constructed using marked, prolix, or unusual forms, this signals that the described situation is itself unusual or unexpected or has special properties;

3. Where an utterance contains an expression drawn from a set of contrasting expressions, assume that the chosen expressions describe a world that itself contrasts with those rival worlds that would have been described by the contrasting expressions.

Both accounts provide explanations of what may happen during the processing of an utterance. In particular, Relevance theory purports to explain how an utterance is processed automatically, bringing to light the cognitive processes underlying the automatic processing of an utterance, while neoGriceans aim at investigating what generates a preferential interpretation, detecting the linguistic and structural aspects of a preferential reading. The two approaches, however, do not take into account the systematic interpretive process involved when an automatic or preferential interpretation is subject to default, namely the reasoning leading to and supporting the choice of an interpretation over another. Neither theory provides a framework for assessing the acceptability of an interpretation, questioning it, and defending it against criticisms. This problem requires a connection between interpretation and argumentation, and more precisely an explanation of the interpretive process in terms of defeasible 
reasoning, namely reasons that can be brought forward, be assessed, questioned, and defended in support of a specific reconstruction of the meaning of an utterance, and that can concern the various interpretive dimensions, from the meaning of a lexical item to the determination of the purpose of an utterance or its implicatures.

A possible way is to represent the interpretive process as a form of reasoning that can be discussed upon and be evaluated to conceive it as an argument aimed at providing the best explanation of the meaning of an utterance, which in turn can be supported by various reasons. Such reasons can be regarded as grounded on defeasible "rules" of reasoning concerning how language is commonly used, how communication is usually conducted, how interlocutors usually behave, etc. In particular, such rules can represent from a reasoning perspective not only the shared conventions or the individual habits of language use, but also behavioral regularities that can be used to predict and account for sentence processing (Altmann and Mirković 2009; Brothers et al. 2015), usually referred to as "scripts" (Schank and Abelson 1977; Samet and Schank 1984)².

Our approach is grounded on the concept of presumption and presumptive reasoning (Atlas and Levinson 1981), namely a pattern of reasoning based on what is usually the case (Thomason 1990), and leading tentative and defeasible conclusions, holding until further conflicting evidence is provided (Walton 1995; Rescher 2006; Macagno 2012; Macagno and Walton 2014, chap. 5). Presumptions work to move the dialogue further when knowledge is lacking. If not rebutted, the proposition representing the conclusion of this pattern of reasoning can be considered as tentatively proved. Rescher represented the structure of this type of inference as follows (Table 2) (Rescher 2006, 33):

\begin{tabular}{|c|l|}
\hline Premise 1: & $\begin{array}{l}P \text { (the proposition representing the presumption) obtains } \\
\text { whenever the condition } C \text { obtains unless and until the } \\
\text { standard default proviso } D \text { (to the effect that } \\
\text { countervailing evidence is at hand) obtains. }\end{array}$ \\
\hline Premise 2: & Condition $C$ obtains (Fact). \\
\hline Premise 3: & Proviso $D$ does not obtain (Exception). \\
\hline Conclusion: & P obtains. \\
\hline
\end{tabular}

Table 2: Presumptive reasoning

For example, we can maintain the aforementioned structure of pragmatic processing represented in figure 1 and provide the presumptive interpretation of the following utterance:

1. You are blackmailing us.

According to this perspective, two patterns of presumptive reasoning are involved. First, the utterance is interpreted relying on the presumptive meaning of the various lexical items, in particular "to blackmail.” Unless other evidence is provided (if the contextual elements available fit the

\footnotetext{
${ }^{2}$ Contemporary approaches to language processing point out the importance of the use of prior knowledge to generate expectations about how a discourse will unfold. Context can activate networks of related concepts or event schemas that can be used to process the utterance (Brothers et al. 2015, 135-136).
} 
interpretation), the tentative conclusion is that the speaker is asserting that, "You are committing the crime of extorting money or other valuable object by threat." In this case, since the utterance asserts an illegal behavior of the interlocutor, it can be taken as an accusation (or complaint), leading to a default of the "literal" meaning of the utterance (Atlas 2005, 15-16). This type of reasoning is grounded on the idea that utterance processing is based on the most accessible, or stereotypical elements of meaning, and that such a presumptive interpretation holds unless rebutted by conflicting contextual information, accessed at the same time (Giora 2003a, 104-105).

Without taking into account all the contextual elements and the presumptions that they carry with them, the interpretive process is only an abstract and idealized model. As Hamblin pointed out, there are several presumptions that act at the same time and contribute to the interpretation of an utterance (Hamblin 1970, 295). The reconstruction of the actions performed by means of an utterance (and the attribution of commitments resulting from them) is matter of assessing together the various presumptions that can emerge in a specific context (Giora 2003a). As Kecskes puts it (Kecskes 2010, p.2895; see also Kecskes 2008):

[...] utterances are not underspecified, and they do not get their full specification from the actual situational context because these linguistic units usually bring as much into the situation as the situation gives them. What gives specification to utterance meaning is neither the actual situational context nor the prior context encoded in the utterances but both.

On this view, an interpretation or interpretive process abstracted from the context, the interaction, the institutional setting, and the background knowledge means only an interpretation in lack of such elements and leading to a conclusion providing a stereotypical representation thereof. In 1 above, the utterance is interpreted regardless of its conversational context by providing a stereotypical intention, a stereotypical context, and a stereotypical setting. If we consider the context, the background information, the type of dialogue or discourse, and the utterance content and type, we reconstruct the meaning of an utterance through several presumptions of different type and level, which result in inferences that are defeasible or non-defeasible (Capone 2005, 1360; Kecskes 2010; Capone 2013). Only when all these factors (presumptions) are evaluated together, we can assess an utterance as ambiguous or not (Bell 1997).

\subsection{Levels of presumption and reasoning from best interpretation}

An interpretation can be supported by providing different types of evidence, related to different types of presumptions concerning what can be shared by the interlocutors (Clark 1996, 113-15; Kecskes 2013, 4; Kecskes and Zhang 2013). They can be divided in four types. Presumptions of the first type (Level 0 - pragmatic presumptions) concern the pragmatic purpose of a speech act, connecting for instance an illocutionary force (assertion) with an intention (informing) (Kecskes 2008; Kecskes and Zhang 2009; Kissine 2012). The second type (Level 1 - Linguistic) refers to presumptions related to the knowledge of linguistic (or rather semantic-ontological) items and structure (called semantic presumptions). For instance, dictionary or shared meanings of lexical items are presumed to be known by the speakers of a language. Such presumptions represent the presumptive meaning of linguistic elements (Hamblin 1970; Levinson 2000; Macagno 2011), which, however, are subject to default in case the context requires a different interpretation (such as in the case of metaphors, see Giora, 2003, p. 60). Other presumptions (Level 2 - Factual, encyclopedic) are about encyclopedic knowledge, such as facts, common connection between events, or behaviors and habits that are shared within a specific community, culture, society. Finally, the last kind of presumptions includes information shared by the interlocutors, i.e. presumptions 
about the interlocutor's behavior or knowledge based on previous conversations, interactions, or other types of evidence. The levels of presumptions can be represented in Figure 1 as follows:

\section{Levels of presumptions}

\begin{tabular}{|c|c|}
\hline 0. Pragmatic & $\begin{array}{c}\text { Use-Act; Type of dialogue-type of move } \\
\text { (ex. Assertive sentences are usually used to } \\
\text { inform the hearer; In eristic dialogues interlocutors } \\
\text { are expected to vent emotions). }\end{array}$ \\
\hline 1. Linguistic & $\begin{array}{c}\text { Definitions, syntactic structures } \\
\text { (ex. 'Man' is usually used to mean a 'rational } \\
\text { animal'). }\end{array}$ \\
\hline 2. Factual, encyclopedic & $\begin{array}{c}\text { Customs, habits and stereotypes } \\
\text { (ex. People usually know that France is not a } \\
\text { monarchy now). }\end{array}$ \\
\hline 3. Mutual, shared & $\begin{array}{l}\text { The interlocutor's interests/values... } \\
\text { (ex. Professor } x \text { is usually very critical and writes } \\
\text { no recommendation letters; } x \text { is usually against } \\
\text { the freedom of press...). }\end{array}$ \\
\hline
\end{tabular}

Figure 1: Levels of presumptions

The co-existence of different interpretations of the propositional content of a speech act, leading to distinct communicative effects (and different legal consequences), does not mean that the two constructions are equally reasonable or acceptable. The assessment of the conflicting interpretations can be carried out systematically by reconstructing and evaluating the argumentative structure underlying them. We consider the logical form encoded by an utterance in terms of presumptions that need to be assessed together with other presumptions also of different kind.

On this view, interpretation becomes the conclusion of an argumentative process of reasoning grounded on the abductive pattern (Atlas 2005, 13) of reasoning from best interpretation (Atlas and Levinson 1981; Atlas 2005), which can be reconstructed as an argumentation scheme from best explanation (Walton et al. 2008):

Argumentation Scheme 1: Reasoning from best explanation

\begin{tabular}{|l|l|}
\hline Premise 1 & $U$ (an utterance) is an observed communicative act. \\
\hline Premise 2 & $\begin{array}{l}I \text { (Interpretation 1) is a satisfactory description of the meaning of } \\
U .\end{array}$ \\
\hline Premise 3 & $\begin{array}{l}\text { No alternative meaning description } I \text { (such as interpretation 2 ) } \\
\text { given so far is as satisfactory as } I \text {. }\end{array}$ \\
\hline Conclusion & $\begin{array}{l}\text { Therefore, } I \text { is a plausible hypothesis, based on what is known so } \\
\text { far. }\end{array}$ \\
\hline
\end{tabular}


Ambiguity is based on the coexistence of two possibly satisfactory interpretations of the utterance in premise 2, which needs to be resolved in premise 3. In particular, when two interpretations are advanced, their defeasibility conditions need to be analyzed considering all the possible contextual evidence available. The less defeasible interpretation is the one that should be preferred.

For instance, example 1 above can be reconstructed by providing the contextual elements and the contextual presumptions leading to the best interpretation. The interpretation of the aforementioned utterance was in fact the crucial issue in one of the leading cases in defamation law (Greenbelt Pub. Assn. v. Bresler, 398 U.S. 6, 1970) (Franklin and Bussel 1983, 831). The context was the following: a developer, Mr. Bresler, held an extremely unreasonable and aggressive negotiating behavior with the city council of the city in which he was doing business, Greenbelt. The discussion became heated, and some council members used the aforementioned utterance to vent their emotions. The newspapers reported the quote in the context, and Bresler accused the journal of defamation. The Court (398 U.S. 13-14) reconstructed the various presumptions and their contextual defaults, and the reasoning structure can be represented in Figure 2 as follows:

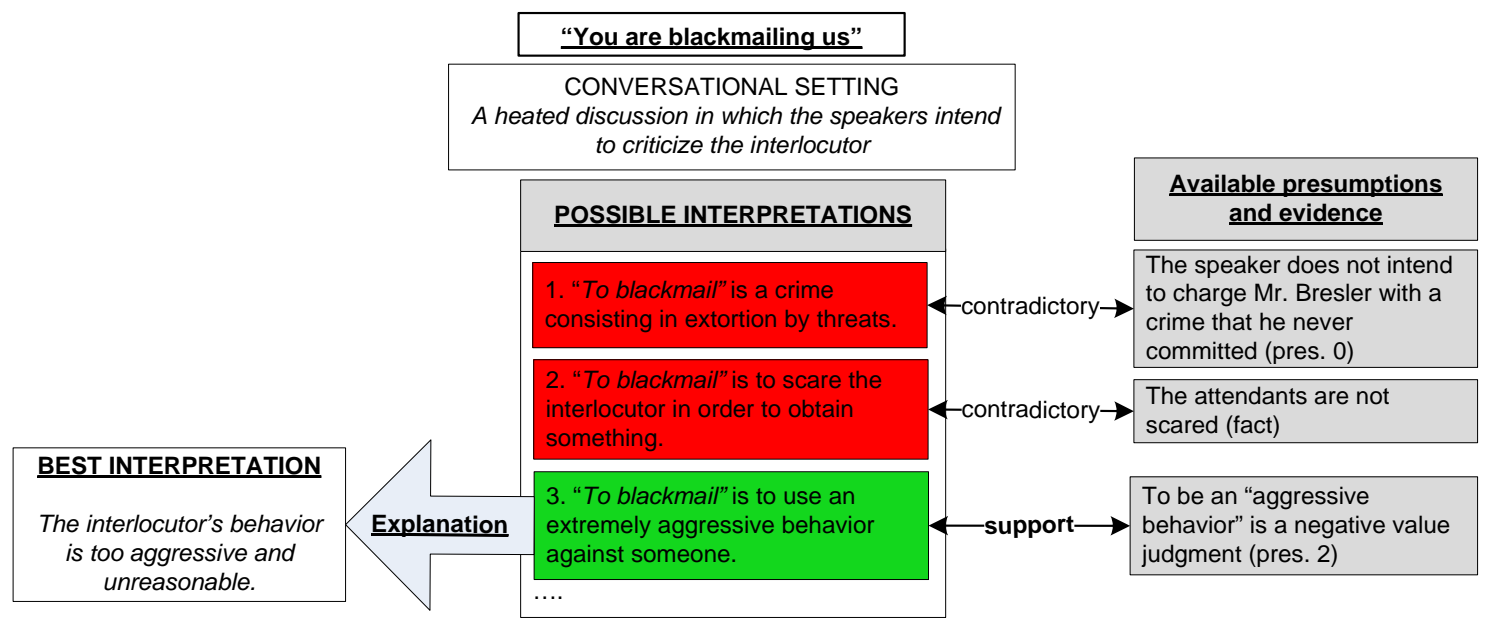

Figure 2: Explaining pragmatic ambiguity

In this case, we notice that the presumptions are evaluated together, but the most important overarching presumption guiding the interpretation is given by the type of dialogue the interlocutors are engaging in. As already noted by Levinson (Levinson 1992) and pointed out by Kecskes (Kecskes and Zhang 2009; Kecskes 2013; Kecskes 2015), interpretation needs to stem from the intended goal of the interaction and contribution of the move to the conversation. For this reason, the type of interaction the interlocutors are engaging in guides the analysis of the various presumptions involved in the interpretive process. To this purpose, we need to introduce the idea of dialogue move as an instrument for representing the presumptive or actual communicative purposes of the interlocutors within an interaction.

\section{Dialogue moves}

In philosophy of language, the notion of "illocutionary force" is commonly used to describe the inherent and constitutive effects of an utterance (Searle and Vanderveken 1985, 92-95). This leads to a description of utterances in terms of intended cognitive responses (Grice 1968; Kissine 2012), which says very little about the effects that an utterance can have on the conversation, or the intentions expressed by non-serious utterances (Kissine 2012, 177), which is one of the crucial elements for 
interpreting an utterance in context (Giora 2003a; Atlas 2005) and the coherence thereof with the rest of the conversation (Bell 1997, 51; Giora 2008). Moreover, the description of some speech acts in cognitive terms does not account for the interactional intention of the speaker, namely the effect he intends to have on the conversation. A speaker performs an assertion for many reasons that cannot be reduced to representing a belief concerning state of affairs. If we do not take into account their interactional and conversational dimension we cannot capture when an utterance is aimed at informing or just reminding of a commitment, or when it is aimed at warning the hearer or threatening him (Grosz and Sidner 1986; Bell 1997; Kissine 2012). A different approach is needed, which we describe in terms of dialogue types and dialogue moves.

\subsection{Dialogue types and communicative intentions}

Instead of conceiving intentions in cognitive terms, it can be more useful to analyze the intentions (and commitments) starting from the communicative purposes of utterances, namely the way they contribute to the "work of the interaction in which it occurs" (Levinson 1983, 291; Geis 1995, 10; 32). In this sense, we need to focus on the joint (social) actions performed by the interlocutors, and not on the individual actions that speech act theory describes (Mey 2001, 214; Kecskes 2010, 2889). Such purposes are captured by neither a speech-act level description nor a sequence-level analysis. A higherlevel classification is needed, in which the individual higher-order intentions that the participants express through their utterances are described according to "conversational demand" (Mann 1988; Dascal 1992; Mey 2001, 163), namely their dialogical and communicative aims (Bunt 2000). The focus is not on the connection between the individual moves, but rather on the relationship between the joint purpose of the dialogue (such as making a decision) and the individual utterances, explaining why a participant is performing a specific “pragmatic act” (Mey 2001, 94) or dialogue act (Bunt 2000) (is he requesting information? Is he trying to persuade the interlocutor?). We will refer to the acts corresponding to the units of dialogue (which can correspond to an utterance, a sequence of utterances, or a part of an utterance) (Grosz and Sidner 1986, 177) as dialogue moves. The underlying intentions will be referred to as "conversational intentions" in the sense of intents (that can be presumed in a given context) to carry out some conversational effects by means of their utterances (or parts or strings thereof) (Bach and Harnish 1979, 7).

On this view, dialogue moves (and utterances) cannot be interpreted independent of their communicative contexts, which involve necessarily an audience or an interlocutor (even only potential). In argumentation theory, communicative contexts are conceived as dialogues, actual or potential, in which the speaker and the audience or the interlocutors pursue a specific joint goal. On this view, dialogical (and communicative) contexts are represented in terms of communicative or dialogical intentions (in the sense of Grosz and Sidner, 1986: 178), which mirror the main purposes of the agents engaging in a discussion (Grice 1975, 45; van Eemeren and Grootendorst 2004, 72).

The joint purposes of a dialogue, namely the interlocutors' generic “we-intentions” of pursuing a joint activity (Searle 2002, 92-94), were classified by Walton (Walton 1989; Walton 1990; Walton and Krabbe 1995; Walton 1998; Macagno 2008) in six “types of dialogue”: persuasion, negotiation, inquiry, deliberation, information seeking, and eristics. The typology of dialogue types, even though non-comprehensive, represents the most common and generic goal-oriented types of dialogical interactions (Dunin-Keplicz \& Verbrugge 2001; McBurney \& Parsons 2009). The types of dialogue are represented in Table 3 below (Walton and Krabbe 1995, 66):

TYPE

\begin{tabular}{c|c} 
INITIAL \\
SITUATION
\end{tabular}

MAIN GOAL
PARTICIPANTS' AIMS
SIDE BENEFITS 


\begin{tabular}{|c|c|c|c|c|}
\hline $\begin{array}{l}\text { 1. Persuasion } \\
\text { Dialogue }\end{array}$ & $\begin{array}{l}\text { Conflicting } \\
\text { points of } \\
\text { view }\end{array}$ & $\begin{array}{l}\text { Resolution of } \\
\text { such conflicts } \\
\text { by verbal means }\end{array}$ & $\begin{array}{l}\text { Persuade the } \\
\text { other(s) }\end{array}$ & $\begin{array}{l}\text { Develop and reveal } \\
\text { positions } \\
\text { Build up confidence } \\
\text { Influence onlookers, } \\
\text { Add to prestige }\end{array}$ \\
\hline 2. Negotiation & $\begin{array}{l}\text { Conflict of } \\
\text { interests \& } \\
\text { need for } \\
\text { cooperation }\end{array}$ & Making a deal & $\begin{array}{l}\text { Get the best out } \\
\text { of it for oneself }\end{array}$ & $\begin{array}{l}\text { Agreement, Build up } \\
\text { confidence } \\
\text { Reveal position } \\
\text { Influence onlookers } \\
\text { Add to prestige }\end{array}$ \\
\hline 3. Inquiry & $\begin{array}{l}\text { General } \\
\text { ignorance }\end{array}$ & $\begin{array}{l}\text { Growth of } \\
\text { knowledge \& } \\
\text { agreement } \\
\end{array}$ & $\begin{array}{l}\text { Find a "proof" } \\
\text { or destroy one }\end{array}$ & $\begin{array}{l}\text { Add to prestige } \\
\text { Gain experience } \\
\text { Raise funds }\end{array}$ \\
\hline 4. Deliberation & $\begin{array}{l}\text { Need for } \\
\text { action }\end{array}$ & $\begin{array}{l}\text { Reach a } \\
\text { decision }\end{array}$ & $\begin{array}{l}\text { Influence } \\
\text { outcome }\end{array}$ & $\begin{array}{l}\text { Agreement } \\
\text { Develop \& reveal } \\
\text { positions } \\
\text { Add to prestige, Vent } \\
\text { emotions }\end{array}$ \\
\hline $\begin{array}{l}\text { 5. Information- } \\
\text { seeking }\end{array}$ & $\begin{array}{l}\text { Personal } \\
\text { Ignorance }\end{array}$ & $\begin{array}{l}\text { Spreading } \\
\text { knowledge and } \\
\text { revealing } \\
\text { positions }\end{array}$ & $\begin{array}{l}\text { Gain, pass on, } \\
\text { show, or hide } \\
\text { personal } \\
\text { knowledge }\end{array}$ & $\begin{array}{l}\text { Agreement } \\
\text { Develop \& reveal } \\
\text { positions } \\
\text { Add to prestige, Vent } \\
\text { emotions }\end{array}$ \\
\hline 6. Eristics & $\begin{array}{l}\text { Conflict \& } \\
\text { antagonism }\end{array}$ & $\begin{array}{l}\text { Reaching a } \\
\text { (provisional) } \\
\text { accommodation } \\
\text { in a relationship }\end{array}$ & $\begin{array}{l}\text { Strike the other } \\
\text { party \& win in } \\
\text { the eyes of } \\
\text { onlookers }\end{array}$ & $\begin{array}{l}\text { Agreement } \\
\text { Develop \& reveal } \\
\text { positions } \\
\text { Gain experience, } \\
\text { Amusement } \\
\text { Add to prestige, Vent } \\
\text { emotions }\end{array}$ \\
\hline
\end{tabular}

Table 3: Types of Dialogue and their Characteristics

The various dialogue types can be used as an instrument for describing and analyzing actual communicative practices. There is a discrepancy, however, between what the dialogue types represent and actual dialogical practices. The aforementioned abstract models of dialogues correspond to higher level communicative aims, such as: information seeking, deliberation, inquiry, persuasion, etc. (Walton and Krabbe 1995). In normative, formal approaches to dialogues, such models can be thought of as protocols that agents need to comply with, and for this reason the moves they are composed of need to belong to the same "game” (Bench-Capon et al. 1991; McBurney and Parsons 2009). However, in an actual dialogue the global communicative aim is achieved through several "dialogue moves" that can be of different nature. For example, a dialogue aimed at making a decision can include phases in which the interlocutors try to support their viewpoint, or share information (Levin and Moore 1977; Mann 1988).

Building on Levinson's idea concerning the relationship between activity types and the role that utterances play within it (Levinson 1992), we can use the idea of dialogue types as the framework of the proposed continuation of a dialogue that a move advances. According to Levinson, the inferences concerning the interpretation of the role of the utterance in a dialogue depend on the activity the 
interlocutors are engaging in (Levinson 1992, 72), which affects the degrees of cooperation and compliance with the maxims. For example, in order to understand how an answer to a question should be interpreted (for example, by drawing the needed implicatures or rather interpreting it literally), it is necessary to begin from the purpose of the dialogue, and determine whether it is aimed at exchanging information (mutual interest of the parties) or proving a conclusion (leading the answering party to admit a point).

This insight can be combined with Van Dijk's approach of macro-structure of dialogue. On his perspective, the global purpose of a discourse cannot be captured by a composition of grammatical units (or their underlying propositions). Rather, the discourse units need to be defined starting from the global purpose (Van Dijk 1977), defined in terms not only of topic, but rather of communicative action or game. According to Van Dijk, discourse coherence needs to be determined not only syntactically (and/or semantically) as connections between sentences, but also pragmatically, namely contribution to a joint communicative purpose (Van Dijk 1977) or appropriateness to a conversational demand (Dascal 1992, 45).

In this sense, the "macro-interpretation" of the type of activity the interlocutors are engaging in and the generic purpose they are pursuing defines the relevance (or importance) of the single units of discourse (Van Dijk 1977). The relationship between moves is defined based on the relationship between the various dialogical intentions and sub-intentions (Levin and Moore 1977).

\subsection{Classifying dialogical intentions}

In a more general sense, the dialogical intentions that the moves instantiate can be described using the typology of Walton and Krabbe (sharing some crucial features with the typology presented in Mann 1988, 515). Such dialogue types, even though non-comprehensive, represent the most common and generic goal-oriented types of dialogical interactions that a move can propose (Dunin-Keplicz and Verbrugge 2001; McBurney and Parsons 2009), which can be further specified by identifying sub-goals or more specific goals related to specific contexts of interaction.

These general moves can be described as in Table 4 (Macagno and Bigi 2017a). The Category indicates the type of move, the Description provides an explanation of the dialogical intention instantiated by the move and the final column provides Examples from (adapted) real dialogues in the context of medical chronic care interviews:

\begin{tabular}{|c|c|c|}
\hline $\begin{array}{c}\text { Category } \\
\text { (Code) }\end{array}$ & $\begin{array}{c}\begin{array}{c}\text { Description of } \\
\text { category }\end{array} \\
\end{array}$ & Example \\
\hline $\begin{array}{l}\text { Information } \\
\text { sharing (IS) }\end{array}$ & $\begin{array}{l}\text { Dialogue moves } \\
\text { aimed at retrieving } \\
\text { and providing } \\
\text { information. }\end{array}$ & $\begin{array}{l}\text { Doctor: I would like to know how you feel, and if your } \\
\text { conditions has changed from the last visit. } \\
\text { Patient: I feel a bit tired. In the last four months, I have } \\
\text { been hospitalized three times. } \\
\text { Doctor: Why? } \\
\text { Patient: I passed out. } \\
\text { Doctor: Were the collapses related to your diabetes? } \\
\text { Patient: Apparently there was no relationship. }\end{array}$ \\
\hline $\begin{array}{l}\text { Persuasion } \\
\text { (P) }\end{array}$ & $\begin{array}{l}\text { Dialogue moves } \\
\text { aimed at persuading } \\
\text { the interlocutor, } \\
\text { leading him or her } \\
\text { to accept a specific } \\
\text { point of view. }\end{array}$ & $\begin{array}{l}\text { Patient: eh I know you should drink drink drink, even } \\
\text { two liters per day } \\
\text { Doctor: Two liters can even be even too much } \\
\text { especially for someone like you who drinks half of } \\
\text { it, but if we do things gradually, your health will }\end{array}$ \\
\hline
\end{tabular}




\begin{tabular}{|c|c|c|}
\hline & & $\begin{array}{l}\text { improve. Drinking improves also your kidney } \\
\text { functionality. }\end{array}$ \\
\hline $\begin{array}{l}\text { Deliberation } \\
\text { (D) }\end{array}$ & $\begin{array}{l}\text { Dialogue moves } \\
\text { aimed at making a } \\
\text { decision. }\end{array}$ & $\begin{array}{l}\text { Doctor: having always the same therapy what is it that } \\
\text { changes? what changes is what you have been } \\
\text { eating } \\
\text { Patient: I don't know but maybe I see something } \\
\text { tempting I eat it and then I realize right away from } \\
\text { this number } \\
\text { Doctor: [exactly] so then at this point what should you } \\
\text { do? } \\
\text { Patient: I shouldn't eat it } \\
\text { Doctor: no one should you should at this point not sit } \\
\text { down but try to [do a little of activity] physical } \\
\text { activity. I know that in the evening one [would sit] } \\
\text { Patient: yes then }\end{array}$ \\
\hline $\begin{array}{l}\text { Negotiation } \\
(\mathrm{N})\end{array}$ & $\begin{array}{l}\text { Dialogue moves } \\
\text { aimed at solving a } \\
\text { conflict of interests } \\
\text { or goals, and } \\
\text { making a joint } \\
\text { decision satisfying } \\
\text { the interests of both } \\
\text { interlocutors. }\end{array}$ & $\begin{array}{l}\text { Doctor: I will fix the next visit in October, so you can } \\
\text { return to Milan } \\
\text { Patient: Ok, or November, if it is possible } \\
\text { Doctor: Let's go for October. I cannot leave you } 9 \\
\text { months without any control. Do you want a visit in } \\
\text { November? } \\
\text { Patient: I wanted to go to the South in October. If it is } \\
\text { at the beginning of October it is ok. } \\
\text { Doctor: Mid-October? } \\
\text { Patient: Ok. }\end{array}$ \\
\hline Eristic (E) & $\begin{array}{l}\text { Dialogue moves } \\
\text { aimed at reaching } \\
\text { an accommodation } \\
\text { in a dialogical } \\
\text { relationship (for } \\
\text { example, defining } \\
\text { roles and offices). }\end{array}$ & $\begin{array}{l}\text { Patient: I no longer take these pills. I thought that they } \\
\text { were too many, and I decided not to take them. } \\
\text { Doctor: Why have you done it? Your values are now } \\
\text { terrible, and we need to intervene with other } \\
\text { treatments. Why have you made such a decision } \\
\text { without consulting us? } \\
\text { Patient: I thought you said so. } \\
\text { Doctor: Look at your therapeutic plan. I have never } \\
\text { said such a thing! You were supposed to take these } \\
\text { pills twice a day! } \\
\text { Patient: I thought... } \\
\text { Doctor: You cannot do such a thing and then blame it } \\
\text { on others! }\end{array}$ \\
\hline
\end{tabular}

Table 4: Categories of the coding scheme

Every discourse move can thus be regarded as a proposal to pursue a dialogue goal (Levin and Moore 1977; Walton and Macagno 2007; Macagno 2008), relevant to a global joint intention (Walton 1989, 68). It needs to interact with the other dialogical moves to reach the higher goal of the dialogue. The interlocutor can accept the proposed interaction (for example, exchanging information, making a decision...) or contribute to the higher goal with an appropriate response, proposing a distinct type of interaction. On this perspective, discourse moves are defined not in terms of individual intentions 
(illocutionary acts), but rather in terms of proposals of joint activities (Mann 1988). They pursue a joint dialogical goal, which can be accepted and continued, or refused and replaced with an appropriate counter-proposal.

In this sense, we can interpret the aforementioned category of "illocutionary ambiguity" as dialogical ambiguity (ambiguity at the level of the interpretation of the dialogue move). Depending on the relationship between the move and its intended effect, we then redefine the previous concept of imaginary ambiguity distinguishing between the following categories:

a. Dialogical ambiguity, or ambiguity of the intended effects that constitute the dialogical goal of the move. For example, a question (Do you think that this behavior is acceptable?) can be interpreted as a deliberation move, encouraging the interlocutor to commit to a certain course of action, or as an information sharing move, demanding an opinion.

b. Perlocutionary ambiguity, or ambiguity consequent to the performance of a move and not directly intended. For example, an assertion (My aunt's dog died today) can be intended to provide a piece of information (Information sharing), but it can result in the hearer's grief (in case he believes that the dog was a source of joy) or relief (in case he believes that the dog was suffering).

c. Indirectly conveyed ambiguity, namely ambiguity of contents that are not explicitly intended, but that are presupposed (implicated by semantic items or syntactic structures) or implied by the speaker. For example, in the following exchange: “Did you have a bank account?" "The company had one," the reply can be considered as ambiguous relatively to its implicature (it can mean that the interrogated person had no bank accounts, but also that he does not intend to answer by providing personal information).

The distinction can be represented as follows:

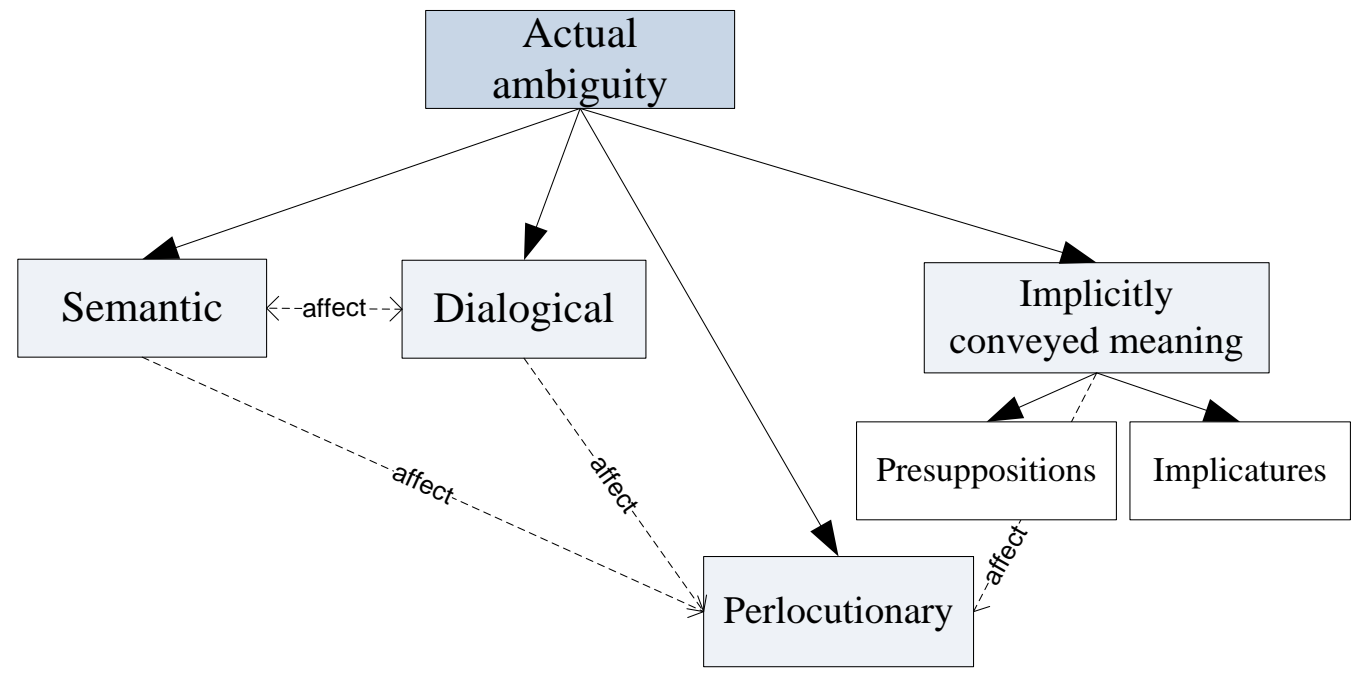

Table 5: Actual ambiguity revisited

In the following section we will analyze ambiguities in chronic care interviews, distinguishing between the different levels of ambiguity.

\section{Interpreting ambiguities in chronic care interviews}


Chronic care consultations about diabetes offer crucial cases of conflicts of presumptions resulting in ambiguities of different kind. Medical interviews can be conceived as instances of intercultural communication (Angelelli 2004; Schouten and Meeuwesen 2006; Bigi 2016, 49-51). On the one hand, the physician is presumed to have a background of scientific knowledge not shared by the interlocutor. On the other hand, the patient's preferences and lifestyle are presumed not to be known by the doctor (Bigi 2011; Bigi 2014a). Moreover, patients and doctors may not share the same cultural background in terms of language, ethnicity, or social class. These factors may result in communication problems at different levels, which unveil underlying presumptions that need to be addressed in order to avoid deeper misunderstanding.

In this paper, we propose examples of analysis from a corpus of diabetes interviews. Our corpus consists of 60 video-recordings of doctor-patient encounters collected at a public diabetes outpatient clinic in northern Italy from 2012 to 2014 (the corpus is described in Bigi 2014b). Apart from the "cultural" differences (Kecskes 2015) stemming from different uses of language and different explanations of scientific facts, in some cases also the very roles of the doctor and the patient are conceived differently. Some patients act based on the presumption that the doctors shall impose a treatment and the patient has no other role than obeying or not obeying. Our analysis was aimed at identifying instances of misaligned presumptions at different levels that could be considered as the causes for such "cultural" differences (Macagno and Bigi 2017b). Indeed, the latter can be conceived as presumptions at various levels that can be subject to default and may result in ambiguity and misunderstanding at a semantic (the language used), encyclopedic (the knowledge about relations between facts or events), pragmatic (presumed communicative intentions), or mutual (how people generally behave or what they like most) level.

\subsection{Semantic ambiguity - lexical ambiguity}

The following excerpt involves a linguistic presumption ${ }^{3}$. In diabetes care, the problem is the control of glycaemia; therefore, a crucial issue is the glycemic index of food. Bread has a high glycemic index, higher than sliced rusk. In some Italian linguistic communities, however, the same word "fette biscottate" can refer to both slices of rusks and slices of toasted bread. The word "biscottato" can refer to the browning of baked food (slices of bread, cake, biscotti), but when used in combination with "fette" ("slices") it is used as a phrase and it refers to "rusk" (Zwieback). The doctor presupposes that it should be clear what the expression "fette biscottate" refers to, because it is an item that belongs to the common knowledge of the Italian community. The patient and his wife seem to focus on the ambiguity of "biscottato" and presuppose that the issue is with toasting bread and not with the nature of the baked good they eat (pre-sliced bread for toast has a higher glycemic index than sliced rusk).

\section{Case 1}

1. D: What do you have for breakfast? Coffee with milk and two fette biscottate (rusk)...

2. P: Two fette biscottate

3. D: or biscotti?

4. P: no, two slices of rusk, toasted bread

5. D: ah! that's a different thing, toasted bread

6. Wife: no, it's not toasted, it's those slices of bread that you can toast but we don't toast it.

7. P: they're from Buitoni

\footnotetext{
${ }^{3}$ This example has been discussed also in (Macagno and Bigi, 2017b).
} 
8. Wife: Mulino Bianco, Buitoni [popular Italian brands of baked goods]

9. D: Buitoni... but, can't you get the normal fette biscottate?

10. P: ehmm...

11. D: the normal ones? Fette biscottate?

12. P: I think those are normal... why, what do you mean by fette biscottate? These are slices

13. D: fette biscottate?

14. P: slices

15. D: all right

The patient (and his wife) and the doctor interact on the basis of different presumptions. At 1 and 9, the doctor presumes that slices of toasted bread are a concept different from rusk, or rather that two distinct words refer to these concepts, and that fette biscottate refers exclusively to rusk ("can't you get the normal fette biscottate?"). On the contrary, at 2, 4, 12, and 14, the patient presupposes that fette biscottate refers to two synonymous concepts, rusk and toasted bread ("two slices of rusk, toasted bread"; "These are slices"). This misunderstanding is based on defaulted and conflicting presumptions on both sides. Both the doctor and the patient presume that the meaning of fette biscottate is shared (linguistic presumption). Moreover, they both ground their interaction on the presumption that the interlocutor knows respectively the equivalence or the difference between rusks and toasted bread for the purposes of diabetes care. On this view, encyclopedic presumptions underlie the linguistic ones: the equivalence (presumed by the patient and disregarded by the doctor) indicates that the speaker does not know that bread is much more detrimental to his condition than rusks. Conversely, the doctor presumes that this difference is shared, and does not insist on this point.

\subsection{Semantic ambiguity - syntactic ambiguity}

In the following excerpt, the nurse is commenting on the patient's parameters and notices that her weight has diminished, which is an improvement for this particular patient.

\section{Case 2}

1. N: Your weight is much better, have you noticed?

2. P: Yes, many thanks for giving me those instructions concerning eating less. You know, sometimes in the evening I almost forget to eat.

3. N: No, eating less does not mean forgetting to eat. You are under medications, so be careful otherwise you risk hypoglycemias.

We noticed in this case a broader interpretation of "eating less" conflicting with a more restricted one. Indeed, the nurse presumes that the patient understands that "eating less" refers to the reduction of the amount of food eaten during each meal, not to the reduction of the food ingested overall. The patient instead seems to be acting on a broader interpretation of "eating less", which includes skipping meals altogether. In this context, however, the broader interpretation conflicts with the factual presumption that not eating will cause risky drops in the levels of the glycaemia, due to the fact that the patient is taking her medications, which were prescribed based on the assumption that the patient is having regular meals.

\subsection{Pragmatic ambiguities}


The last example is a more complex one, involving two types of pragmatic ambiguity, dialogical and perlocutionary. In the history taking phase the doctor observes a worsening of the general situation of the patient's diabetes. She then starts looking into his self-monitoring journal and notices values that do not fully explain this global worsening. So, she looks into the glucometer and finds out that the patient has measured very high values but has not written them in the journal.

In a rather abrupt manner, she begins a dialogical move in which she explains to the patient why it is important for him to write into the journal all the values he measures.

\section{Case 3}

1. D: [not answering the patient, but as though talking to herself] 291 is almost 300; 299... that's why the values are so strange. So, dear Mr. Smith, the things you write in here [pointing to the journal] are for yourself, they are not for me, is this clear? We are collaborating, right now I have an agreement with you, I am accompanying you, to help you. But the goal of our meeting must be that your health improves, that you feel better, that you are well. If you don’t display all the information, I cannot help you improve.

2. P: yes yes [tries to say something but D stops him and keeps talking]

This move seems to presuppose that the patient has fully understood the function of the journal, the need for the self-monitoring in relation to the customization of the therapy and the urgency of keeping his glucose values below a certain level. It also seems to presuppose that the patient has intentionally not written the higher values in the journal. The patient does not reply much, except displaying certain impatience at the doctor's talk.

At the end of the doctor's turn, when she ends by pointing out that the very high values that had not been transcribed in the journal have contributed to increasing the overall glucose parameter (HbA1c), the patient's wife replies (at 12) by asking: “so, what can be the cause of this situation?”, thereby demonstrating that she failed to understand the pragmatic function of the doctor's previous moves.

3. D: now, if you don't write them of course you are damaging yourself. You are the one who is feeling worse

4. P: basically I am not writing all of my values

5. D: and this is wrong because you are the first person, you are the first person...

6. P: yees [sounding impatient]

7. D: who should become aware of the fact: look here, I have had hyperglycemias, I got up to 300, what did I do?

8. P: what, what, why did this happen?

9. D: exactly, you are the first person who should do this kind of work, then you can talk to us and we are always here for you

10. P: to give explanations

11. D: but I see you today with a glycated hemoglobin of 9 after seeing you with a 7.3, which was perfect for your age, and I think, what happened?

12. Wife: yes, right, what happened? what do you think it depends on?

13. P: this difference, this sudden change?

The ambiguity problem we see in this excerpt has to do with the interpretation of the dialogical function of an explanation. The doctor's pragmatic presumption is that her dialogical move consists in 
offering the patient reasons and data for making a specific decision: to write into the journal all the measured values. The patient, instead, seems to presume that the doctor is trying to inform him of higher values regarding his glycaemia, and asks for the reason thereof.

The pragmatic misunderstanding is at a twofold level, a local and a global one. At a local level, the Wife's reply at 12 shows the misunderstanding of the dialogical purpose (the speaker's intention) resulting in a different interpretation of the perlocutionary effect of the doctor's rhetorical question at 11. The doctor wants to express his puzzlement at worrying values that are not documented by the only evidence that the patient can provide on his habits and condition, i.e. his updated journal. The doctor's question is intended to express the seriousness of the effects of the patient's failure to comply with the instructions. It is aimed at backing up her global communicative intention, consisting in committing more strongly the patient to updating the journal correctly (deliberations moves). However, the wife's reply - backed by the patient - is a reply to an interpretation of the doctor's question as an expression of uncertainty or difficulty to explain the increased values ("eristic" moves, aimed at venting emotions). If we use the speech act classification, she interprets the doctor's speech act not as an assertive act (I cannot retrieve the information that I need for understanding the values) supporting a directive (you should update the journal), but rather as an expressive (I do not know what happened).

At a global level, the moves mirror that the interlocutors are engaging in different dialogues. The wife (and the patient) are interpreting the doctor's words as a mere provision of information regarding a worrying situation (information sharing). The doctor's presumption that the patient is aware of the gravity of his behavior (deliberation dialogue), which constitutes a risk for himself, is not confirmed by the patient's reaction. The patient responds as though he were listening to a provision of information about facts that happened independently of his will.

\section{Conclusion}

In this paper we claim that ambiguities and the possible misunderstandings resulting from them are not simply interpretive problems. They can reveal much deeper cultural differences, which can be of fundamental importance for the purposes of communication. Our theoretical approach is grounded on the notion of interpretation as the best explanation of meaning (Atlas and Levinson 1981; Atlas 2007; Atlas 2008) and the corresponding heuristic mechanisms underlying meaning understanding (Dascal and Wróblewski 1988; Dascal 2003). Our focus, however, is not on the processing and the mechanisms triggered to interpret an utterance (Giora 2003a), but more specifically on the possible arguments and the possible argumentative structure that can be used to support or justify an interpretation. To this purpose, the insights and the advances provided by linguistic pragmatics can be used with a different target.

On this argumentation perspective, both in the case of heuristic and systematic processing, utterances are interpreted based on presumptions and hierarchies of presumptions working at the same time, namely defeasible rules used to draw conclusions in situations of lack of knowledge. The presumptive interpretation used to automatically process the utterance leads to a prima facie meaning, which holds until it is challenged or subject to default (until communicative problems arise from this interpretation). In order to establish a presumptive or non-presumptive reading and the possible defeasibility conditions thereof, it is necessary to assess the possible presumptions that can contribute to establish the meaning, including the pragmatic presumptions concerning the goal of the conversation. The analysis of the contextual presumptions can lead to an interpretation that is less subject to refutation, and thus can be used to solve the possible ambiguity of an utterance. A fundamental implication of this view is that ambiguity can arise because of different presumptions at different levels. If the interlocutors do not share the same linguistic, pragmatic, factual, and mutual presumptions, they can provide different interpretations supported by different reasons. 
Misunderstandings thus become signals of ambiguities, and ambiguities can reveal deeper cultural differences.

This theoretical framework can be highly relevant in professional contexts, in which due to differences in education, society, or context, the interlocutors can have communication problems due to pragmatic misunderstandings. Bringing out the causes of these conflicting meanings can lead to a better understanding of deeper differences. In particular, in the medical context detecting and addressing the presumptions underlying pragmatic misunderstanding can shed light on the patient's presumptions characterizing his choices, his values, and his ideas about doctor-patient interactions. Within the ideal medical communication model of shared decision making and the paradigm of patient-centered communication (Stewart 1995; Arora and McHorney 2000; Bigi 2014b), the doctor's awareness of the presumptions underlying ambiguity and the argumentative mechanism for tackling them can become crucial.

\section{References}

Aikin, Scott F., and John Casey. 2011. Straw Men, Weak Men, and Hollow Men. Argumentation 25: 87-105. doi:10.1007/s10503-010-9199-y.

Altmann, Gerry, and Jelena Mirković. 2009. Incrementality and Prediction in Human Sentence Processing. Cognitive science 33: 583-609.

Angelelli, Claudia. 2004. Medical Interpreting and Cross-cultural Communication. Cambridge: Cambridge University Press.

Aristotle. 1991. Topics. In The complete works of Aristotle, vol. I, ed. Jonathan Barnes. Princeton: Princeton University Press.

Arora, N K, and C a McHorney. 2000. Patient preferences for medical decision making: who really wants to participate? Medical care 38: 335-341. doi:http://dx.doi.org/10.1097/00005650200003000-00010.

Atlas, Jay David. 1989. Philosophy without Ambiguity: A Logico-linguistic Essay. Oxford: Clarendon Press.

Atlas, Jay David. 2005. Logic, Meaning, and Conversation. Oxford: Oxford University Press. doi:10.1093/acprof:oso/9780195133004.001.0001.

Atlas, Jay David. 2007. Meanings, propositions, context, and semantical underdeterminacy. In Contextsensitivity and semantic minimalism: new essays on semantics and pragmatics, ed. Gerhard Preyer and Georg Peter, 217-239. Oxford: Oxford University Press.

Atlas, Jay David. 2008. Presupposition. In The Handbook of Pragmatics, ed. Laurence Horn and Gregory Ward, 29-52. Oxford: Blackwell Publishing Ltd. doi:10.1002/9780470756959.ch2.

Atlas, Jay David, and Stephen Levinson. 1981. It-clefts, informativeness and logical form: Radical pragmatics (revised standard version). In Radical pragmatics, ed. Peter Cole, 1-62. New York: Academic Press.

Bach, Kent, and Robert Harnish. 1979. Linguistic communication and speech acts. Cambridge, Mass.: MIT Press.

Bell, David. 1997. Innuendo. Journal of Pragmatics 27: 35-59.

Bench-Capon, Trevor J M, PAUL E Dunne, and Paul H Leng. 1991. Interacting with knowledge-based systems through dialogue games. In Proceedings of the Eleventh International Conference on Expert Systems and Applications, 123-140. Avignon.

Bezuidenhout, Anne. 1997. Pragmatics, semantic undetermination and the referential/attributive distinction. Mind 106: 375-409. doi:10.1093/mind/106.423.375.

Bigi, Sarah. 2011. The persuasive role of ethos in doctor-patient interactions. In Communication and 
Medicine, 8:67-75. doi:10.1558/cam.v8i1.67.

Bigi, Sarah. 2014a. Key components of effective collaborative goal setting in the chronic care encounter. Communication and Medicine 11: 1-13. doi:10.1558/cam.v11i2.21600.

Bigi, Sarah. 2014b. Healthy Reasoning: The Role of Effective Argumentation for Enhancing Elderly Patients’ Selfmanagement Abilities in Chronic Care. In Active Ageing and Healthy Living: A Human Centered Approach in Research and Innovation as Source of Quality of Life, ed. Giovanni Riva, Paolo Ajmone Marsan, and Claudio Grassi, 193-203. Amsterdam: IOS Press.

Bigi, Sarah. 2016. Communicating (with) care. A linguistic approach to the study of interactions in chronic care settings. Amsterdam: IOS Press.

Brothers, Trevor, Tamara Swaab, and Matthew Traxler. 2015. Effects of Prediction and Contextual Support on Lexical Processing: Prediction Takes Precedence. Cognition 136: 135-149.

Bunt, Harry. 2000. Dialogue pragmatics and context specification. In Abduction, Belief and Context in Dialogue. Studies in Computational Pragmatics, ed. Harry Bunt and William Black, 81-150. Amsterdam: John Benjamins Publishing.

Capone, Alessandro. 2005. Pragmemes (a study with reference to English and Italian). Journal of Pragmatics 37: 1355-1371. doi:10.1016/j.pragma.2005.01.013.

Capone, Alessandro. 2009. Are explicatures cancellable? Toward a theory of the speaker's intentionality. Intercultural Pragmatics 6: 55-83. doi:10.1515/IPRG.2009.003.

Capone, Alessandro. 2011. The Attributive/Referential Distinction, Pragmatics, Modularity of Mind and Modularization. Australian Journal of Linguistics 31: 153-186. doi:10.1080/07268602.2011.560827.

Capone, Alessandro. 2013. Explicatures are NOT Cancellable. In Perspectives on Linguistic Pragmatics, Perspectives in Pragmatics, Philosophy \& Psychology 2, ed. Alessandro Capone, Franco Lo Piparo, and Marco Carapezza, 131-151. Cham: Springer.

Carston, Robyn. 2002a. Pragmatics and linguistic undeterminacy.

Carston, Robyn. 2002b. Thoughts and utterances: the pragmatics of explicit communication. Oxford: Blackwell Publishing Ltd.

Carston, Robyn. 2013. Legal texts and canons of construction: a view from current pragmatic theory. In Law and language: current legal issues, ed. Michael Freeman and Fiona Smith, 15:8-33. Oxford: Oxford University Press.

Dascal, Marcelo. 1992. On the pragmatic structure of conversation. In (On) Searle on conversation, ed. Herman Parret and Jef Verschueren, 35-57. Amsterdam-Philadelphia: John Benjamins Publishing.

Dascal, Marcelo. 2003. Interpretation and understanding. Amsterdam: John Benjamins Publishing Company.

Dascal, Marcelo, and Jerzy Wróblewski. 1988. Transparency and doubt: understanding and interpretation in pragmatics and in law. Law and Philosophy 7: 203-224.

Deppermann, Arnulf. 2000. Semantic Shifts in Argumentative Processes: A Step Beyond the "Fallacy of Equivocation.” Argumentation 14: 17-30. doi:10.1023/A:1007838727096.

Van Dijk, Teun. 1977. Semantic macro-structures and knowledge frames in discourse comprehension. In Cognitive processes in comprehension, ed. Marcel Adam Just and Patricia Carpenter, 3-32. Hillsdale, NJ: Lawrence Erlbaum Associates.

Dunin-Keplicz, B, and R Verbrugge. 2001. The role of Dialogue in Cooperative Problem solving. In Proceedings of the 5th International Symposium on Logical Formalization of Commonsense reasoning, New York, ed. Ernest Davis, John McCarthy, Leora Morgenstern, and Raymond Reiter, 89-104. New York.

van Eemeren, Frans, and Rob Grootendorst. 2004. A systematic theory of argumentation: The pragmadialectical approach. Cambridge: Cambridge University Press.

Elman, Jeffrey. 1990. Finding Structure in Time. Cognitive Science 14: 179-211. 
Flores, Glenn. 2000. Culture and the patient-physician relationship: achieving cultural competency in health care. The Journal of pediatrics 136: 14-23. doi:http://dx.doi.org/10.1016/S00223476(00)90043-X.

Franklin, Marc, and Daniel Bussel. 1983. The Plaintiff's Burden in Defamation: Awareness and Falsity. William and Mary law review 25: 825-889.

Geis, Michael. 1995. Speech Acts and Conversational Interaction. Cambridge: Cambridge University Press.

Giora, Rachel. 2003a. On our mind. Salience, Context, and Figurative Language.

Giora, Rachel. 2003b. On Our Mind. Salience, Context, and Figurative Language. Oxford: Oxford University Press. doi:10.1093/acprof:oso/9780195136166.001.0001.

Giora, Rachel. 2008. Is Metaphor Unique? In The Cambridge Handbook of Metaphor and Thought, ed. Raymond Gibbs, 143-160. New York: Cambridge University Press.

Grice, Paul. 1968. Utterer's meaning, sentence meaning and word-meaning. Foundations of Language 4: 225-242.

Grice, Paul. 1975. Logic and conversation. In Syntax and semantics 3: Speech acts, ed. Peter Cole and Jerry Morgan, 41-58. New York: Academic Press.

Grosz, Barbara, and Candace Sidner. 1986. Attention, intentions, and the structure of discourse. Computational linguistics 12. MIT Press: 175-204.

Gundel, Jeanette K., and Thorstein Fretheim. 2004. Topic and Focus. Edited by Laurence Horn and Gregory Ward. The Handbook of Pragmatics. London: Blackwell: 175-196. doi:10.1002/9780470756959.ch8.

Hamblin, Charles Leonard. 1970. Fallacies. London: Methuen.

Jaszczolt, Katarzyna. 1999. Discourse, beliefs and intentions. Oxford: Elsevier.

Kecskes, Istvan. 2008. Dueling contexts: A dynamic model of meaning. Journal of Pragmatics 40: 385-406. doi:10.1016/j.pragma.2007.12.004.

Kecskes, Istvan. 2010. Situation-bound utterances as pragmatic acts. Journal of Pragmatics 42: 28892897.

Kecskes, Istvan. 2013. Intercultural pragmatics. Oxford: Oxford University Press.

Kecskes, Istvan. 2015. Intracultural communication and intercultural communication: Are they different? International Review of Pragmatics 7: 171-194. doi:10.1163/18773109-00702002.

Kecskes, Istvan, and Fenghui Zhang. 2009. Activating, seeking, and creating common ground: A sociocognitive approach. Pragmatics \& Cognition 17: 331-355. doi:10.1075/pc.17.2.06kec.

Kecskes, Istvan, and Fenghui Zhang. 2013. On the Dynamic Relations Between Common Ground and Presupposition. In Perspectives on Linguistic Pragmatics, Perspectives in Pragmatics, Philosophy \& Psychology 2, ed. Alessandro Capone, Franco Lo Piparo, and Marco Carapezza, 375-395. Cham: Springer. doi:10.1007/978-3-319-01014-4_15.

Kissine, Mikhail. 2012. Sentences, utterances, and speech acts. In Cambridge handbook of pragmatics, ed. Keith Allan and Kasia Jaszczolt, 169-190. New York: Cambridge University Press. doi:10.1017/cbo9781139022453.010.

van Laar, Jan Albert. 2001. Ambiguity in a dialectical perspective. Informal Logic 21: 245-266. van Laar, Jan Albert. 2003. The Dialectic of Ambiguity. Groningen: Rijksuniversiteit Groningen. Levin, James, and James Moore. 1977. Dialogue-games: Metacommunication structures for natural language interaction. Cognitive science 1. Elsevier: 395-420. doi:10.1016/S0364-0213(77)800165.

Levinson, Stephen. 1983. Pragmatics. Cambridge: Cambridge University Press.

Levinson, Stephen. 1992. Activity types and language. In Talk at work: Interaction in institutional settings, ed. Paul Drew and John Heritage, 66-100. Cambridge: Cambridge University Press.

Levinson, Stephen. 2000. Presumptive meanings: The theory of generalized conversational 
implicature. Cambridge, Mass.: MIT Press.

Lyons, John. 1977. Semantics. Cambridge: Cambridge University Press.

Macagno, Fabrizio. 2008. Dialectical relevance and dialogical context in Walton's pragmatic theory. Informal logic 28: 102-128.

Macagno, Fabrizio. 2011. The presumptions of meaning: Hamblin and equivocation. Informal Logic 31: 368-394.

Macagno, Fabrizio. 2012. Presumptive reasoning in interpretation. Implicatures and conflicts of presumptions. Argumentation 26. Springer Netherlands: 233-265. doi:10.1007/s10503-011-92329.

Macagno, Fabrizio. 2016. Reporting and Interpreting Intentions in Defamation Law. In Indirect Reports and Pragmatics, ed. Alessandro Capone, Ferenc Kiefer, and Franco Lo Piparo, 593-619. Cham: Springer. doi:10.1007/978-3-319-21395-8.

Macagno, Fabrizio, and Sarah Bigi. 2017a. Analyzing the pragmatic structure of dialogues. Discourse Studies 19: 148-168.

Macagno, Fabrizio, and Sarah Bigi. 2017b. Understanding misunderstanding: Presuppositions and presumptions in doctor-patient chronic care consultations. Intercultural Pragmatics 14: 49-75.

Macagno, Fabrizio, and Alessandro Capone. 2016. Interpretative disputes, explicatures, and argumentative reasoning. Argumentation 30: 399-422. doi:10.1007/s10503-015-9347-5.

Macagno, Fabrizio, and Giovanni Damele. 2013. The dialogical force of implicit premises: Presumptions in enthymemes. Informal Logic 33: 361-389.

Macagno, Fabrizio, and Douglas Walton. 2014. Emotive Language in Argumentation. Cambridge: Cambridge University Press. doi:10.1017/CBO9781139565776.

Mann, William C. 1988. Dialogue games: Conventions of human interaction. Argumentation 2. Springer: 511-532.

McBurney, Peter, and Simon Parsons. 2009. Dialogue games for agent argumentation. In Argumentation in artificial intelligence, ed. Guillermo Simari and Iyad Rahwan, 261-280. Heidelberg: Springer.

Mey, Jacob. 1993. Pragmatics: An Introduction. Oxford: Blackwell Publishers.

Mey, Jacob. 2001. Pragmatics. An introduction. Oxford: Blackwell.

Mey, Jacob. 2003. Context and (dis)ambiguity: a pragmatic view. Journal of Pragmatics 35: 331-347. doi:10.1016/S0378-2166(02)00139-X.

Patterson, Dennis. 2004. Interpretation in Law. San Diego Law Review 42: 685-710.

Récanati, François. 1987. Meaning and force : the pragmatics of performative utterances. New York: Cambridge University Press.

Reinhart, Tanya. 1981. Pragmatics and linguistics: An analysis of sentence topics in pragmatics and philosophy. Philosophica 27: 53-94.

Rescher, Nicholas. 2006. Presumption and the Practices of Tentative Cognition. Cambridge: Cambridge University Press. doi:10.1017/CBO9780511498848.

Saka, Paul. 2007. How to Think About Meaning. Dordrecht: Springer.

Samet, Jerry, and Roger Schank. 1984. Coherence and connectivity. Linguistics and philosophy 7: 5782.

Schank, Roger, and Robert Abelson. 1977. Scripts, Plans, Goals and Understanding. An Inquiry into Human Knowledge Structures. Hillsdale, NJ: Lawrence Erlbaum Associates.

Schouten, Barbara, and Ludwien Meeuwesen. 2006. Cultural differences in medical communication: a review of the literature. Patient education and counseling 64: 21-34. doi:10.1016/j.pec.2005.11.014.

Searle, John. 1976. A classification of illocutionary acts. Language in society 5: 1-23. doi:10.1017/s0047404500006837. 
Searle, John. 2002. Consciousness and Language. New York: Cambridge University Press.

Searle, John, and Daniel Vanderveken. 1985. Foundations of illocutionary logic. Cambridge: Cambridge University Press.

Searle, John, and Daniel Vanderveken. 2005. Speech acts and illocutionary logic. In Logic, Thought and Action, 109-132. Dordrecht: Springer Netherlands.

Soames, Scott. 2008. Philosophical essays, volume 1. Natural language: what it means and how we use it. Princeton: Princeton University Press.

Sperber, Dan, and Deirdre Wilson. 1986. Relevance: Communication and Cognition. Oxford: Blackwell.

Stewart, Moira. 1995. Effective physician-patient communication and health outcomes: A review. CMAJ.

Thomason, Richmond. 1990. Accommodation, meaning, and implicature: Interdisciplinary foundations for pragmatics. In Intentions in communication, ed. Philip Cohen, Jerry Morgan, and Martha Pollack, 325-364. Cambridge: MIT Press.

Walton, Douglas. 1989. Informal logic. New York: Cambridge University Press.

Walton, Douglas. 1990. What is Reasoning? What is an Argument? Journal of Philosophy 87: 399419. doi:10.2307/2026735.

Walton, Douglas. 1995. Argumentation Schemes for Presumptive Reasoning. Mahwah: Routledge. doi:10.4324/9780203811160.

Walton, Douglas. 1996a. Fallacies Arising from Ambiguity. Dordrecht: Kluwer Academic Publishers.

Walton, Douglas. 1996b. The straw man fallacy. In Logic and Argumentation, ed. Johan van Bentham, Frans van Eemeren, Rob Grootendorst, and Frank Veltman, 115-128. Amsterdam: Royal Netherlands Academy of Arts and Sciences.

Walton, Douglas. 1998. The New Dialectic. Conversational contexts of argument. Toronto: University of Toronto Press.

Walton, Douglas. 2006. Using conversation policies to solve problems of ambiguity in argumentation and artificial intelligence. Pragmatics \& Cognition 14: 3-36. doi:10.1075/pc.14.1.03wal.

Walton, Douglas, and Erik Krabbe. 1995. Commitment in dialogue. Albany: State University of New York Press.

Walton, Douglas, and Fabrizio Macagno. 2007. Types of dialogue, dialectical relevance and textual congruity. Anthropology \& Philosophy 8: 101-119.

Walton, Douglas, and Fabrizio Macagno. 2010. Wrenching from context: The manipulation of commitments. Argumentation 24. Springer: 283-317. doi:10.1007/s10503-009-9157-8.

Walton, Douglas, Christopher Reed, and Fabrizio Macagno. 2008. Argumentation Schemes. New York: Cambridge University Press. doi:10.1017/CBO9780511802034.

Wilson, Deirdre. 2016. Relevance Theory. In The Oxford handbook of pragmatics, ed. Yan Huang. Oxford: Oxford University Press. doi:10.1075/pbns.37.

Wilson, Deirdre, and Dan Sperber. 2004. Relevance theory. In Handbook of Pragmatics, ed. Laurence Horn and Gregory Ward, 607-632. Oxford: Blackwell. doi:10.1016/j.pragma.2009.09.021. 